\title{
A broad field of management control
}

\author{
Wolfgang Berens
}

Received: 27 January 2014 / Accepted: 27 January 2014 / Published online: 25 February 2014

(C) Springer-Verlag Berlin Heidelberg 2014

This issue of JoMaC contains three articles illustrating the broad field of management control and the diversity of research methods. The topics addressed in this issue cover management control systems from three perspectives, ranging from rules and routines in management accounting over empirical findings about asymmetric cost behavior to control systems in innovative companies. The study by Bertz and Quinn explores the role of rules in rules/routines interactions. Based on semi-structured interviews conducted at two Irish local authorities that introduced a new cost accounting system, the authors shed light on the question how accounting rules are interpreted and how management accounting routines develop. The interviews reveal the relations between formal and informal rules, human cognition and management accounting routines.

Haustein, Luther, and Schuster use a contingency theory approach to explore what determines the design of management control systems in innovative firms. More precisely, based on a broad literature research and interviews conducted with managers of such firms, the authors identify eleven contingency factors that should be considered. Haustein, Luther, and Schuster then develop formal predictions how these factors relate to direct (results and action control) and indirect controls (personnel and cultural controls) in innovative companies. They conclude that indirect controls better fit the specific contingencies of theses firms. To inspire additional empirical research in the future, the authors suggest measures for an empirical test of their hypotheses.

The paper by Guenther, Riehl, and Rößler provides a concise survey of the cost stickiness literature. Cost stickiness describes the phenomenon of asymmetric cost behavior, i.e. costs are found to increase more when firm activity increases than they fall when activity decreases. The authors discuss four groups of reasons for this asymmetric cost behavior. After introducing a model frequently used to detect cost stickiness,

\footnotetext{
W. Berens $(\varangle)$

Münster, Germany

e-mail: controll@uni-muenster.de
} 
Guenther, Riehl, and Rößler present the results of related empirical research that examines the existence of sticky costs using various samples and the determinants of cost stickiness. Further, limitations of current empirical research in this field are discussed. The authors illustrate the practical consequences of cost stickiness and explore valuable avenues for future research.

I hope that you will enjoy reading these articles and thereby gain useful new insights. 